\title{
Role of folic acid on fetal cardiac morphogenesis
}

\author{
*Pritam Bandyopadhyay ${ }^{1}$, Mahuya Lahiri², Yoshita Kuhu ${ }^{3}$
}

Sri Lanka Journal of Child Health, 2021; 50(2): 233-238

\begin{abstract}
Introduction: Folic acid (FA) deficiency in pregnancy may profoundly affect fetal cardiovascular morphogenesis.
\end{abstract}

Objectives: To evaluate the protective role of FA consumption during pregnancy on genesis of congenital heart disease (CHD).

Method: In this case-control study, 50 children having CHD (cases group) were compared with 99 healthy children (controls group) with regard to history of maternal consumption of supplemented FA during pregnancy. All data about consumption of supplemented FA with duration during antenatal period were obtained based on in-person interviews with both parents. Finally data were analysed and compared between groups.

Results: The commonest CHD in this study was ventricular septal defect (VSD). There was no difference between supplemented FA consumption during pregnancy between the two groups. Study also shows that FA supplementation in pregnancy significantly decreases the incidence of VSD in the cases group.

Conclusions: The study reveals that supplemented FA consumption during pregnancy significantly reduces the risk of CHD.

DOI: http://dx.doi.org/10.4038/sljch.v50i2.9563

(Key words: Congenital heart defect, folic acid supplementation, pregnancy)

${ }^{1}$ Head of Department and Assistant Professor,
${ }^{2}$ Assistant Professor, ${ }^{3}$ Senior Resident, Department
of Paediatrics, ESIC-PGIMSR \& ESIC Medical
College \& Hospital, Joka, Kolkata, West Bengal,
India
${ }^{* C o r r e s p o n d e n c e: ~ p r i t a m b a n e r j e e 86 @ g m a i l . c o m ~}$

https://orcid.org/0000-0003-1232-9578

(Received on 13 May 2020: Accepted after revision on 19 June 2020)

The authors declare that there are no conflicts of interest

Personal funding was used for the project.

Open Access Article published under the Creative Commons Attribution CC-BY (C) (i) License

\section{Introduction}

The incidence and types of congenital heart disease (CHD) vary among countries ${ }^{1}$. The incidence of CHD is approximately $0.5 \%-0.8 \%$ of live births and is higher in spontaneous abortions, stillborns and preterm babies ${ }^{2,3}$. Aetiology of most CHD is unknown and combined genetic and environmental factors may be involved ${ }^{2}$. Recent studies show that consumption of folic acid (FA) in the periconceptional period may play an important role in cardiac morphogenesis ${ }^{4}$. A water soluble vitamin B complex, FA is available in green leafy vegetables. It is converted to dihydrofolates and tetrahydrofolates in the liver and takes an active part in cell division, synthesis, repair, methylation of deoxyribonucleic acid (DNA) and as cofactor of other vital functions ${ }^{5,6}$.

\section{Objectives}

To evaluate the protective role of FA consumption during pregnancy on the occurrence of CHD.

\section{Method}

This is a hospital based, observational, case-control study conducted in ESIC-PGIMSR \& ESIC Medical College and Hospital, Joka, Kolkata, India, a tertiary care hospital, from 01/02/2019 to 31/01/2020, where 50 children with CHD (Cases group) were compared with 99 healthy children without CHD (Control group) in terms of FA consumption of mother during pregnancy. It was a random selection from the children attending paediatric outpatient department (OPD). After taking written informed consent from parents that their participation in the study was voluntary, these children were examined clinically for any congenital heart defect which was subsequently confirmed by echocardiography by a single paediatric cardiologist (to avoid individual variations). Children having congenital heart defects were the "Cases" and children found to have no cardiac disease clinically or by echocardiography were the "controls".

Exclusion criteria for both "Cases" and "Controls" included the following:

1. Parents not willing to participate by providing informed consent

2. Children having valvular heart disease, genetic disorder, cardiomyopathy, single umbilical artery or cardiac rhythm defect.

3. Children having anomalies which are known to be associated with folic acid deficiency like neural tube defect. 
4. Children having acquired heart disease like Rheumatic heart disease.

The subject of the study was explained to the parents in simple colloquial language and written consent was obtained from them. The results of echocardiography were recorded. The semistructural interview was conducted with both parents and the interviewer was blinded for the two groups in obtaining information about FA consumption from mothers and parents. Period of FA consumption during pregnancy and in the preconceptional period, if any, was recorded. Availability of FA (Govt. dispensary/ health worker/chemist shop) and iron +folic acid or only folic acid were both considered as folic acid consumption and included in the study.

Under the protocol of National Iron + initiative, iron and folic acid supplements were given to pregnant mothers, lactating women and adolescent girls at health facilities and outreach activities free of cost by health workers. The present protocol recommends giving oral iron and folic acid tablets to all the pregnant mother during $2^{\text {nd }}$ and $3^{\text {rd }}$ trimesters. The recommended prophylactic dose is one tablet, containing $100 \mathrm{mg}$ elemental iron +0.5 $\mathrm{mg}$ folic acid, once daily preferably after morning meal/ lunch for a period of 6 months during pregnancy and continued another 6 months postpartum. In case mother is anaemic, the dose to be doubled i.e. one tablet after lunch and one after dinner. So folic acid is taken with iron in pregnancy'

Statistical analysis: The study specific data were collected in a case record form (CRF). The data from the CRF were transcribed onto an Excel database and analysed using $\mathrm{R}$ statistical software (Language) version 3.6.1 and $\mathrm{R}$ Studio version 1.0.136 ( $\mathrm{R}$ foundation). Categorical variables were analysed by using Fisher's exact test. Differences between the groups for numerical variables were analysed using ANOVA. The level of significance was set at $5 \%$ for all comparisons.

Ethical issues: Ethical approval was obtained from the Institutional Ethics Committee of ESICPGIMSR AND ESIC Medical College, Joka, Kolkata, India (No. 412. DEAN-JOKA/IEC/2014$15 /$ Vol I). All parents were informed about the research method. Written informed consent was obtained from the parents of the participants.

\section{Results}

The frequency of congenital cardiac anomalies in the Cases group is shown in Table 1.

Table 1: Frequency of congenital cardiac anomalies in Cases group

\begin{tabular}{|l|c|}
\hline \multicolumn{1}{|c|}{ Type of cardiac lesion } & Frequency (\%) \\
\hline Ventricular septal defect (VSD) & $16(32)$ \\
\hline VSD with patent ductus arteriosus (PDA) & $12(24)$ \\
\hline Atrial septal defect (ASD) & $09(18)$ \\
\hline ASD with PDA & $10(20)$ \\
\hline Tetralogy of Fallot & $02(04)$ \\
\hline d-Transposition of great arteries & $01(02)$ \\
\hline
\end{tabular}

The commonest congenital cardiac defect was ventricular septal defect (VSD). In our case group, out of 50 children 28 had VSD either as a solitary defect or in combination with patent ductus arteriosus (PDA).
A summary of the Cases and Control groups is shown in Table 2.

Table2: Summary of the Cases and Control group

\begin{tabular}{|l|c|c|c|}
\hline \multicolumn{1}{|c|}{ Characteristic } & Cases (A) $(\boldsymbol{n}=\mathbf{5 0})$ & Controls (B) $(\boldsymbol{n}=\mathbf{9 9})$ & p value \\
\hline Gender & $17(34 \%)$ & $49(49.5 \%)$ & 0.105 \\
Female - n (\%) & $33(66 \%)$ & $50(50.5 \%)$ & 0.03 \\
Male - n (\%) & $16.2(12.8)$ & $24.0(18.1)$ & \\
\hline Age in months - Mean ( SD) & $18(36.0 \%)$ & $49(49.5 \%)$ & 0.264 \\
\hline Folic acid used & $15(30.0 \%)$ & $26(26.3 \%)$ & \\
After 12 weeks - n (\%) & $17(34.0 \%)$ & $24(24.2 \%)$ & \\
Before 12 weeks - n (\%) & & & \\
Never - n (\%) &
\end{tabular}

There was no significant difference in gender frequency of the 2 groups as shown in Table 2. No significant difference has been noted among the folic acid users before and after $1^{\text {st }}$ trimester (12 weeks) in the 2 groups as shown in Table 2 $(\mathrm{p}>0.05)$. 
The period of folic acid consumption and cardiac anomalies distribution is shown in Figure 1.
VSD was the commonest cardiac defect in nonusers of folic acid during pregnancy as shown in Figure 1.

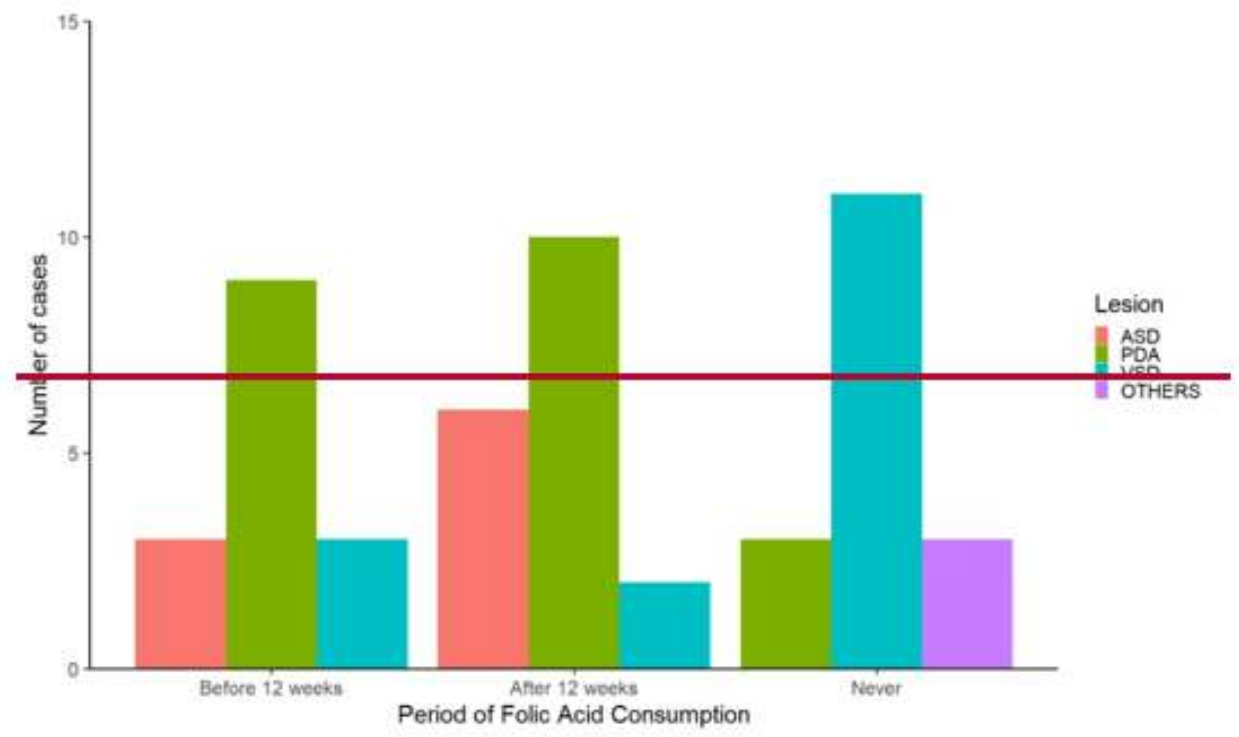

Figure 1: Period of folic acid consumption and cardiac anomalies distribution

The age distribution of cardiac defects is shown in Table 3. There was no significant difference in age distribution among cardiac defects $(\mathrm{p}>0.05)$.
The significance of folic acid consumption periods and cardiac defects is shown in Table 4.

Table3: Age distribution of cardiac defects

\begin{tabular}{|l|c|c|c|c|c|}
\hline & ASD $(\mathbf{n}=9)$ & Others $(\mathbf{n}=\mathbf{3})$ & SD +PDA (n=22) & VSD (n=16) & p -overall \\
\hline Age in months Mean (SD) & $19.9(18.1)$ & $09.0(08.2)$ & $16.2(11.2)$ & $15.6(12.6)$ & 0.644 \\
\hline
\end{tabular}

ASD: atrial septal defect, PDA: patent ductus arteriosus, VSD: ventricular septal defect, SD: shunt defect (ASD/VSD)

Table 4: Significance of folic acid consumption periods and cardiac defects

\begin{tabular}{|l|c|c|c|c|}
\hline \multicolumn{1}{|c|}{ Lesion } & After 12 weeks $(\boldsymbol{n}=\mathbf{1 8})$ & Before 12 weeks $(\boldsymbol{n}=15)$ & Never $(\boldsymbol{n}=17)$ & p -overall \\
\hline ASD & $06(33.3 \%)$ & $03(20.0 \%)$ & $0(0.00 \%)$ & \\
\hline Others & $0(0.00 \%)$ & $0(0.00 \%)$ & $03(17.6 \%)$ & $<0.001$ \\
PDA with VSD/ASD & $10(55.6 \%)$ & $09(60.0 \%)$ & $03(17.6 \%)$ & \\
\hline VSD & $02(11.1 \%)$ & $03(20.0 \%)$ & $11(64.7 \%)$ & \\
\hline
\end{tabular}

ASD: atrial septal defect, PDA: patent ductus arteriosus, VSD: ventricular septal defect

Incidence of VSD was more in the group where mother never used folic acid supplementation and it is statistically significant $(\mathrm{p}<0.001$ by Fisher's exact test). The same was not apparent in other congenital heart defects.

\section{Discussion}

This study shows that the risk of CHD among supplemented FA users during pregnancy is less than among nonusers. In recent studies, there have been both positive and negative associations regarding preventive effects of FA supplementation during pregnancy and the risk of CHD in offspring $^{1,7-11}$. Evidence that supplemented FA taken in the antenatal period will significantly reduce the risk of CHD is supported by data from the Hungarian randomized control trial $(\mathrm{RCT})^{12,13}$ and 2 population based case control studies in the United States of America ${ }^{14,15}$. The Hungarian RCT showed that supplementation of $800 \mu \mathrm{g}$ of FA was associated with about $50 \%$ reduction of the risk of a broad range of congenital cardiac malformations ${ }^{4,8,16}$. In the Atlanta PCC study, periconceptional folic acid supplementation was associated with $24 \%$ decrease of CHD [OR-0.76 (95\%CI $0.60-0.97)$ ] and this study concluded that periconceptional use of folic acid supplementation significantly reduces congenital heart malformations ${ }^{2,14}$. Our study also shows that significant risk of congenital heart defects (VSD) was associated with the nonusers of supplemented folic acid during pregnancy (Table 4). Czeizel AE in RCT study revealed that CHD (mainly VSD) was reduced by $58 \%$ [OR 0.42 (95\%CI $0.19-0.98)$ ] 
if folic acid was supplemented in the antenatal programme compared to others who received only trace elements but not folic acid ${ }^{8,12}$. VSD is also the commonest cardiac defect in our study. Further, a large population based case control study in Netherlands showed that $20 \%$ reduction of any congenital heart defects among supplemented FA users either alone or combined with multivitamins compared with nonusers [OR 0.62 (95\%CI 0.47 $0.82)]^{17}$.

Indirect evidence for use of FA to reduce CHD was shown by Hernandez-Diaz $\mathrm{S}$, et $a l^{18}$, where periconceptional use of medications acting as antifolates, double the risk of VSD and other cardiac defects [OR 2.2(95\%CI 1.4-3.5)]. The precise role of FA in cardiac morphogenesis is not known, but recent methylation hypothesis shows that FA prevents cardiac defects by stimulating cellular methylation reaction ${ }^{19}$. Animal experiment studies also revealed that folic acid supplementation can reduce incidence of congenital heart defects ${ }^{20,21}$. There are also other studies where no definite relationship was found in occurrence of CHD among the users and nonusers of supplemented FA in pregnancy ${ }^{22}$. Werler MM, et al ${ }^{23}$ in their hospital based case control study, showed that there was no effect on the risk of VSD [OR 1.2 (95\%CI 0.8-1.8)] and other cardiac defects associated with periconceptional use of multivitamins containing FA. Similar observations have been made by Scanlon $^{22}$ in outflow tract defects [OR 0.97 (95\%CI 0.6-1.6)]. Nobakht $\mathrm{M}$, et $a l^{24}$ did not find any significant difference in cardiac defects between the two groups regarding supplemented FA consumption in periconceptional period $(\mathrm{p}>0.05)$.

The strength of our study is the data obtained through interviews with the parents of two groups, cases having CHD and controls without CHD or any other disease (normal infants) on the effect of supplemented FA and the interviewers were blinded about the 2 groups. Bailey LB, et $a l^{15}$ concluded that FA is essential for normal fetal cardiac development. This study also showed periconceptional use of folic acid may reduce the risk of congenital cardiac defect significantly. Our study also showed that significant reduction of congenital heart defects may be associated with supplemented FA during pregnancy $(p<0.001)$. The limitations of our study were the small sample size of the study population and lack of FA estimation since this facility was not available in our hospital.

\section{Conclusions}

This study reveals that supplemented FA consumption during pregnancy significantly reduces the risk of CHD $(\mathrm{p}<0.001)$.

\section{Acknowledgements}

The authors are grateful to Dr. Kaushik Mukhopadhyay, Assistant Professor (Pharmacology) ESIC-PGIMSR \& ESIC Medical College, Joka, Kolkata, for the assistance in statistical analysis and Professor (Dr) Joydeb Roychowdhury, Dean, ESIC-PGIMSR \& ESIC Medical College, Joka, Kolkata, for conducting the study. We are also thankful to all mothers who participated and cooperated with interest in the study

\section{References}

1. Tantchou Tchoumi JC, Butera G, Giamberti A, Ambassa JC, Saddeu JC. Occurrence and pattern of congenital heart disease in a rural area of sub-Saharan Africa. Cardiovascular Journal of Africa 2011; 22(2): 63-6.

https://doi.org/10.5830/CVJA-2010-046

PMid: 21556446 PMCid: PMC3721952

2. Berstein D. Epidemiology and genetic basis of congenital heart disease in: Kliegman RN, Blum NJ, Shah SS, Geme JW, Tasker RC, Wilson KM, Behrman RE. Nelson Textbook of Pediatrics, $21^{\text {st }}$ ed. Philadelphia: Elsevier; 2020. pp. 236770 .

3. Brickner ME, Hillis LD, Lange RA. Congenital heart disease in adults, First of two parts. New England Journal of Medicine 2000; 342(4): 256-63. https://doi.org/10.1056/NEJM2000012734 20407

PMid: 10648769

4. Czeizel AE, Dobo $M$, Vargha $P$. Hungarian cohort-controlled trial of periconceptional multivitamin supplementation shows a reduction in certain congenital abnormalities. Birth Defects Research Part A. Clinical and Molecular Teratology 2004; 70(11):85361.

https://doi.org/10.1002/bdra.20086

PMid: 15523663

5. Bailey SW, Ayling JE. The extremely slow and variable activity of dihydrofolate reductase in human liver and its implications for high folic acid intake. Proceedings of the National Academy of Sciences of the United States of America 2009: 106(36): 154249.

https://doi.org/10.1073/pnas.0902072106

PMid: 19706381 PMCid: PMC2730961 
6. Barrowclough D, Ford F. Folic acid fortification. Proposed UK recommendation. The Practising Midwife $2000 ; 3(6): 32-3$

7. Botto LD, Mulinare J, Erickson JD. Occurrence of congenital heart defects in relation to maternal multivitamin use. American Journal of Epidemiology 2000; 151(9): 878-84.

https://doi.org/10.1093/oxfordjournals.aje. a010291

PMid: 10791560

8. Czeizel AE. Periconceptional folic acid containing multivitamin supplementation. European Journal of Obstetrics and Gynecology and Reproductive Biology 1998; 78(2):151-61.

https://doi.org/10.1016/S03012115(98)00 061-X

9. Shaw GM, O’Malley CD, Wasserman CR, Tolarova MM, Lammer EJ. Maternal periconceptional use of multivitamins and reduced risk of conotruncal heart defects and limb deficiencies among offspring. American Journal of Medical Genetics 1995; 59(4): 536-45.

https://doi.org/10.1002/ajmg.1320590428 PMid: 8585581

10. Botto LD, Correa A. Decreasing the burden of congenital heart anomalies; an epidemiologic evaluation of risk factor and survival. Progress in Pediatric Cardiology 2003; 18:111-21. https://doi.org/10.1016/S10589813(03)00 084-5

11. Botto LD, Olney RS, Erickson JD. Vitamin supplements and the risk for congenital anomalies other than neural tube defects. American Journal of Medical Genetics 2004; 125C:12-21.

https://doi.org/10.1002/ajmg.c.30004

PMid: 14755429

12. Czeizel AE. Prevention of congenital abnormalities by periconceptional multivitamin supplementation. British Medical Journal 1993; 306:1645-8 https://doi.org/10.1136/bmj.306.6893.164 5

PMid: 8324432 PMCid: PMC1678103

13. Czeizel AE, Dudas I. Prevention of the first occurrence of neural tube defects by periconceptional vitamin supplementation.
New England Journal of Medicine 1992; 327: $1832-5$

https://doi.org/10.1056/NEJM1992122432

72602

PMid: 1307234

14. Butto LD, Mulinare J, Erickson JD. Do multivitamin or folic acid supplements reduce the risk of congenital heart defects? Evidence and gaps American Journal of Medical Genetics Part A. 2003; 121A (2): 95-101.

https://doi.org/10.1002/ajmg.a.20132

PMid: 12910485

15. Bailey LB, Berry RJ. Folic acid supplementation and occurrence of congenital heart defects, orofacial clefts, multiple births and miscarriage. American Journal of Clinical Nutrition 2005; 81(5): $1213 \mathrm{~s}-1217 \mathrm{~s}$.

https://doi.org/10.1093/ajcn/81.5.1213

PMid: 15883454

16. Czeizel AE. Reduction of urinary tract and cardiovascular defects by periconceptional multivitamin supplementation. American Journal of Medical Genetics 1996; 62:179-83.

https://doi.org/10.1002/(SICI)10968628(1 9960315)62:2<179::AIDAJMG12>3.0.C O;2-L

17. van Beynum IM, Kapusta I, Bakker MK, den Heijer M, Blom HJ, de Walle HE. Protective effect of periconceptional folic acid supplements on the risk of congenital heart defects: a registry based case-control study in the northern Netherlands. European Heart Journal 2010; 31(4): 464-71.

https://doi.org/10.1093/eurheartj/ehp479

PMid: 19952004

18. Hernandez-Diaz S, Werler MM, Walker AM, Mitchell AA. Folic acid antagonists during pregnancy and the risk of birth defects. New England Journal of Medicine 2000; 343(22):1608-14. https://doi.org/10.1056/NEJM2000113034 32204

PMid: 11096168

19. Blom HJ, Shaw GM, den Heijer M, Finnel RH. Neural tube defects and folate: case far from closed. Nature Reviews Neuroscience 2006; 7(9): 724-31. https://doi.org/10.1038/nrn1986 PMid: 16924261 PMCid: PMC2970514 
20. Serrano M, Han M, Brinez P, Linask KK. Fetal alcohol syndrome: cardiac birth defects in mice and prevention with folates. American Journal of Obstetrics and Gynecology 2010; 203(1): e7-75. https://doi.org/10.1016/j.ajog.2010.03.017 PMid: 20451895

21. Mone SM, Gillman MW, Miller TL, Herman EH, Lipshultz SE. Effect of environmental exposure on the cardiovascular system: prenatal period through adolescence. Pediatrics 2004; 113(4 suppl):1058-69.

22. Scanlon KS, Ferencz C, Loffredo CA, Wilson PD, Correa Villasenor A, Khoury $\mathrm{MJ}$, et al. Periconceptional folate intake and malformations of the cardiac outflow tract. Baltimore-Wasington infant study group. Epidemiology1998; 9(1):95-8. https://doi.org/10.1097/000016481998010 00-00019

PMid: 9430276
23. Werler MM, Hayes C, Louik C, Shapiro S, Mitchell AA. Multivitamin supplementation and risk of birth defects. American Journal of Epidemiology 1999; 150(7):675-82

https://doi.org/10.1093/oxfordjournals.aje. a010070

PMid: 10512421

24. Nobakht M, Oveisi S. Folic acid and prevention of congenital heart disease: Yes or No. Biotechnology and Health Sciences 2018; 5(1): e12195 